\title{
Pn wave velocity and anisotropy beneath Pamir and its adjacent regions*
}

\author{
Biao Feng ${ }^{1,2}$ and Shunping Pei ${ }^{1, *}$ \\ ${ }^{1}$ Key Laboratory of Continental Collision and Plateau Uplift, Institute of Tibetan Plateau Research, \\ Chinese Academy of Sciences, Beijing 100101, China \\ ${ }^{2}$ University of Chinese Academy of Sciences, Beijing 100049, China
}

\begin{abstract}
As the western end point of continental collision between the Indian and Eurasian plates, Pamir is an ideal place to research uplifting mechanisms in the Tibetan plateau. In this study, $141644 \mathrm{Pn}$ arrivals were used to obtain seismic wave velocities and anisotropy in the uppermost mantle beneath Pamir and its adjacent regions by performing tomographic inversion of Pn travel times. The data were selected from multiple databases, including ISC/EHB, the Annual Bulletin of Chinese Earthquakes, and regional bulletins of Xinjiang. The tomography results reveal significant features with high resolution and correlate well with geological structures. The main results are as follows: (1) The Pn wave velocities are particularly high in the old stable blocks such as Tarim basin, Indian plate and Tajik basin, while the low Pn velocities always lie in tectonically active regions like the western Tibetan plateau, Pamir, Tianshan and Hindu Kush. (2) Strong Pn anisotropy is found beneath the Indian-Eurasian collision zone; its direction is parallel to the collision arc and nearly perpendicular to both the direction of maximum compression stress and relative crustal movement. The result is probably caused by the pure shear deformation in the uppermost mantle of the collision zone. (3) A geodynamic continent-continent collision model is proposed to show anisotropy and collision mechanisms between the Indian plate and the Tarim and Tajik basins.
\end{abstract}

Key words: Pn wave velocity; tomography; anisotropy; Pamir CLC number: P315.2 Document code: A

\section{Introduction}

As the largest and the youngest continentcontinent orogenic belt, the Indian-Eurasian collision zone is an optimal place to research plate tectonics and orogenic movement. The continental collision began in the Early Paleozoic with sequential accretion, from north to south, of several microcontinents, flysch complexes and island arcs onto the southern margin of Eurasian plate (Chang and Zheng, 1973; Molnar and Tapponnier, 1975; Yin and Harrison, 2000). Pamir, located in this collision zone, displays some of the strongest deformation along the Himalayan orogenic

\footnotetext{
* Received 11 August 2012; accepted in revised form 20 September 2012; published 10 December 2012.

* Corresponding author. e-mail: peisp@itpcas.ac.cn

(c) The Seismological Society of China, Institute of Geophysics, China Earthquake Administration, and Springer-Verlag Berlin Heidelberg 2012
}

belt, as evidenced by its extensive folds, fault blocks, and seismic activity. Figure 1 shows the tectonic framework in Pamir and its adjacent regions.

In recent years, a variety of seismic tomography methods have been used to investigate the velocity structure of the crust underneath and around Pamir. Lei et al. (2002) modeled the three-dimensional seismic velocity structure in the crust and upper mantle down to the depth of $210 \mathrm{~km}$ beneath Pamir and its adjacent regions. $\mathrm{Xu}$ et al. (2006) obtained the $\mathrm{P}$ wave velocity structure of the Tianshan-Pamir conjunctive zone, revealing the heterogeneity of crustal structure and its relations with seismic activity. McNamara et al. (1997) used the Pn arrival time to map the lateral velocity variation within the uppermost mantle in and around the Tibetan plateau. Curtis and Woodhouse (1997) and Mahdi and Pavlis (1998) studied the velocity structure of crust and upper mantle in a larger range by surface wave phase velocity inversion. 
Pn travel-time tomography (Hearn and Ni, 1994; Hearn, 1996) is a very appropriate method to research the velocity structure of uppermost mantle because (1) Pn rays travel in the upper mantle along the Moho discontinuity and have relative abundant arrival time records, and (2) Pn travel time tomography can obtain not only the velocity structure but also the anisotropy of uppermost mantle (usually not considered in most 3D tomography). In recent years, the Pn tomography method has been widely adopted to research different areas near or around Pamir, such as Xinjiang (Pei et al., 2002), the East Himalaya Syntax (Cui and Pei, 2009), central Tianshan (Li et al., 2007), Sichuan (Li et al., 2011) and the whole Indian-Eurasian collision belt (Wang et al., 2001, 2003; Liang et al., 2004; Liang and Song, 2006; Pei et al., 2007, 2011). In these studies, the Pamir area was often relegated to the margin of the study area, resulting in lower solution or absent anisotropy. In this study, we will focus on the Pn tomography of the Pamir and its surrounding regions, including an anisotropy inversion to comprehensively understand the geodynamics and deformation of the area.

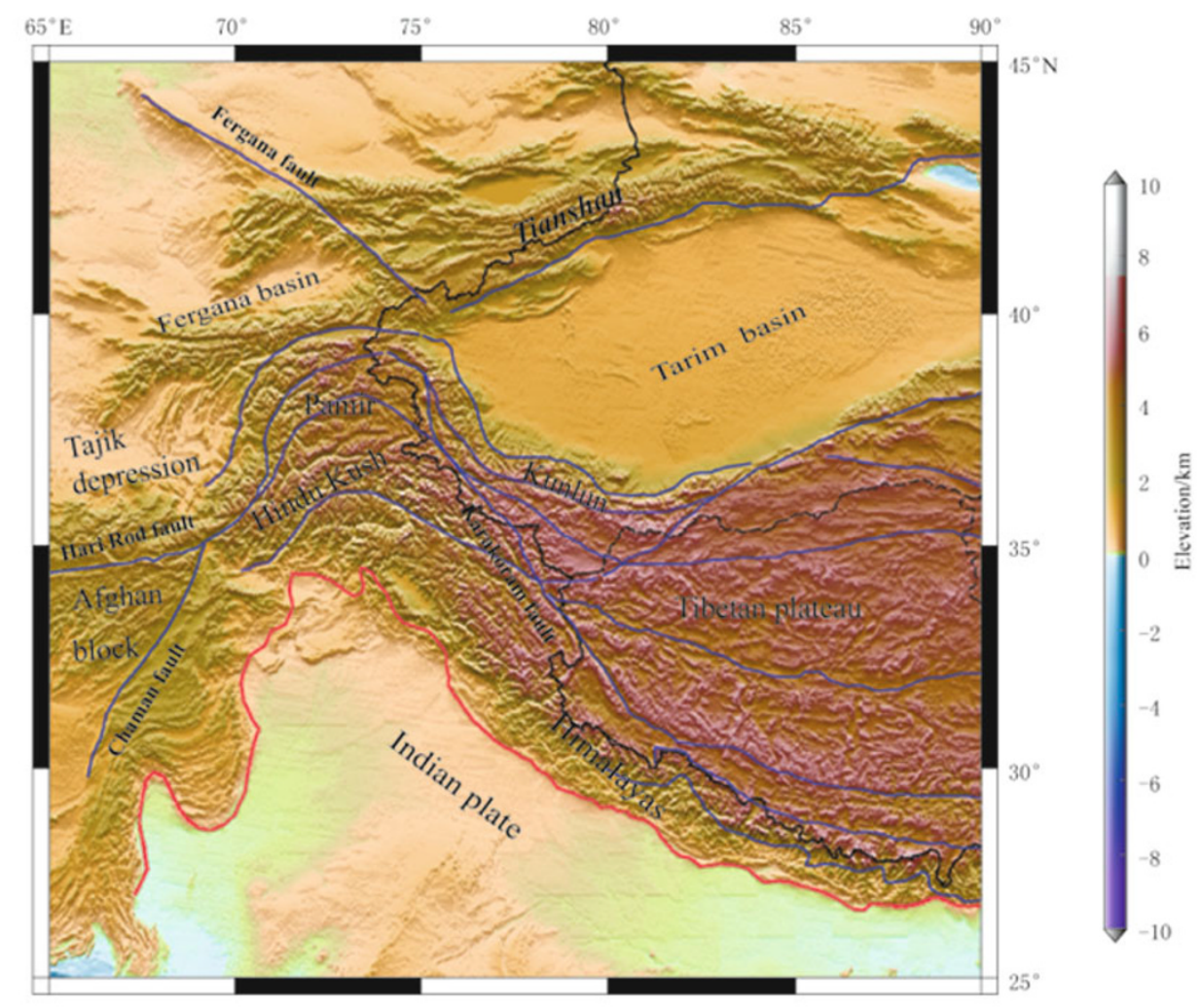

Figure 1 Tectonic framework around Pamir. The blue and red lines represent faults and the plate boundary, respectively.

\section{Data and method}

Our study area is defined by $45^{\circ} \mathrm{N}-60^{\circ} \mathrm{N}$ and $65^{\circ} \mathrm{E}-$ $90^{\circ} \mathrm{E}$. The phase data used in this paper was selected from the following sources: the 1964-2008 International Seismological Center Bulletins, the 1980-2008 Xinjiang regional bulletins, the 1985-2008 Annual Bulletin of Chinese Earthquakes compiled by Institute of Geophysics, China Earthquake Administration, the 19941995 temporary network of project INDEPTH 2, and the 1991-1992 PASSCAL data. Following criteria are adopted to ensure the quality and quantity of data: (1) the epicentral distance is within $2^{\circ}-12^{\circ}$; (2) the local depth is limited to less than $50 \mathrm{~km}$; (3) each event was recorded by at least five stations; (4) each station was recorded at least five events. After the above selecting criteria have been used to discriminate the data, we applied an iterative linear regression algorithm to derive our initial model for the average Pn velocity. The data with travel time residuals (relative to the initial model) larger than $6.0 \mathrm{~s}$ are discarded. Finally $141644 \mathrm{Pn}$ arrivals selected from 18903 events recorded by 451 stations were used to invert for Pn velocity variation and anisotropy. Figure 2 shows the resulting dense distribu- 
tion of ray paths in Pamir and its surrounding region.

We follow the basic inversion scheme of Pn tomography (Hearn, 1996; Pei et al., 2007). Pn is the refractive wave of Moho, and if we divide the surface of upper mantle into the $20^{\prime} \times 20^{\prime}$ grids, the Pn travel time residuals can be defined by the following equation:

$$
t_{i j}=a_{i}+b_{j}+\sum d_{i j k}\left(s_{k}+A_{k} \cos 2 \phi+B_{k} \sin 2 \phi\right),
$$

where, $t_{i j}$ is the travel time residual from the $j$ th earthquake to the $i$ th station; $a_{i}$ is the static delay of $i$ th station; $b_{j}$ is the static delay for the $j$ th event; $d_{i j k}$ is the distance traveled by ray $i j$ in the mantle cell $k ; s_{k}$ is the slowness perturbation for cell $k ; A_{k}, B_{k}$ are the anisotropy coefficients for cell $k ; \phi$ is the back- azimuth. The magnitude of $\mathrm{Pn}$ anisotropy for cell $k$ is $\left(A_{k}^{2}+B_{k}^{2}\right)^{1 / 2}$ and the fast direction of $\operatorname{Pn}$ is $\theta=$ $\left[\arctan \left(B_{k} / A_{k}\right)\right] / 2+90^{\circ}$. We used the LSQR method to resolve all unknown quantities, and two damping constants were used to control the smoothness of velocity and anisotropy. Because the results would be better when the two constants are held to be equal (Hearn and $\mathrm{Ni}, 1994$ ), we adopted the same damping constants for slowness and anisotropy in our inversion. After some tests, a final damping constant of 1300 was selected. Additional details of the tomography technique used in this study can be found in the papers by Hearn and $\mathrm{Ni}$ (1994) and Hearn (1996).

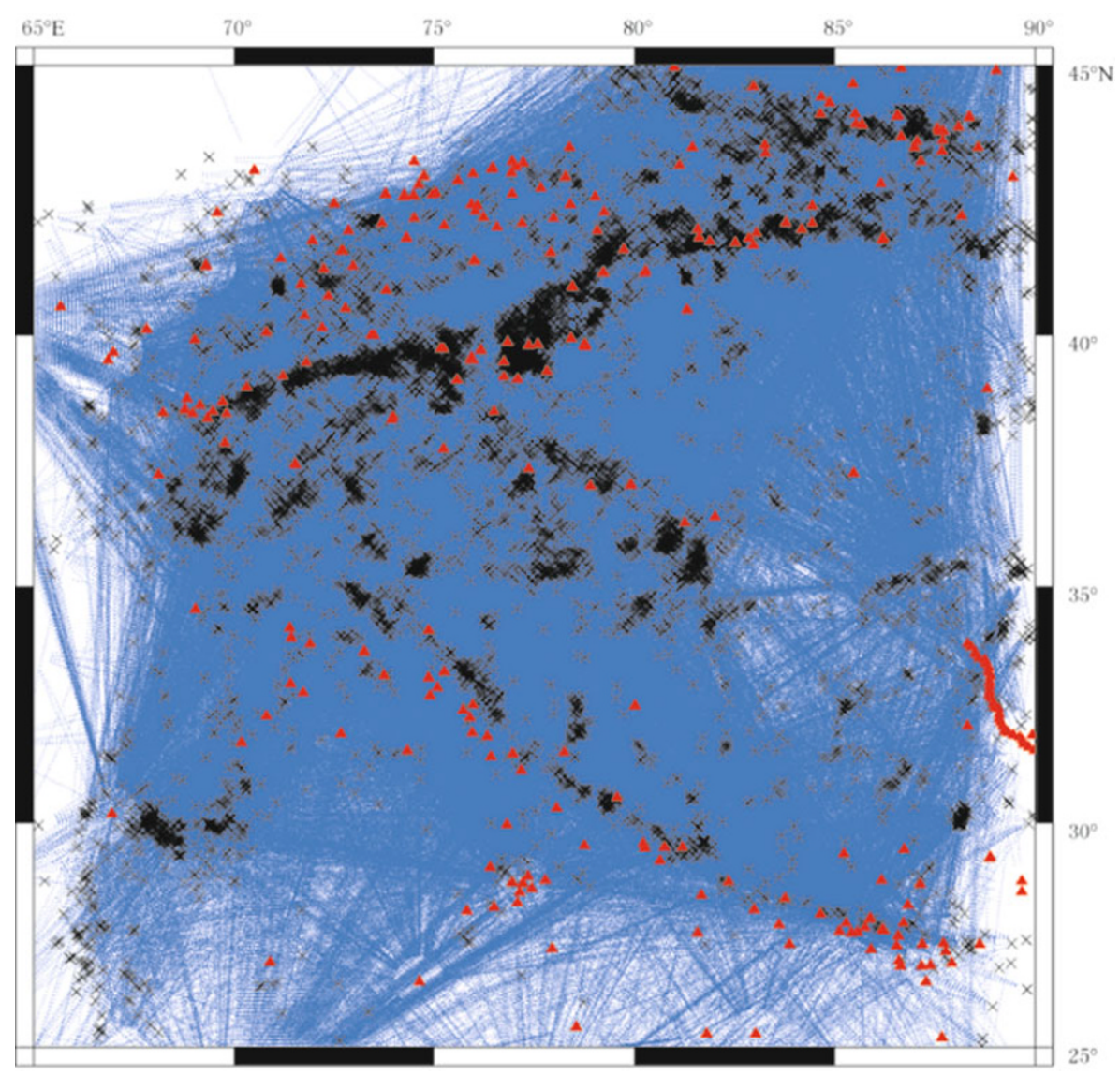

Figure 2 Pn ray paths of the data set and the distribution of earthquakes (crosses) and stations (red triangles).

\section{Results}

\subsection{Pn velocity}

Fitting a straight line to the data set of Pn travel time versus epicentral distance, we obtained an average Pn velocity of $8.25 \mathrm{~km} / \mathrm{s}$, which is higher than previous results (Pei et al., 2007, 2011) due to additional data contributed in this study. Figure 3 shows the Pn lateral velocity variations, with red and blue corresponding to low and high velocity anomalies, respectively. Relative to the average velocity of $8.25 \mathrm{~km} / \mathrm{s}$, the velocity perturbations are in the range from $-0.32 \mathrm{~km} / \mathrm{s}$ to $0.29 \mathrm{~km} / \mathrm{s}$. After the inversion, the standard deviation of travel time residuals decreased from $2.08 \mathrm{~s}$ to $1.28 \mathrm{~s}$. 


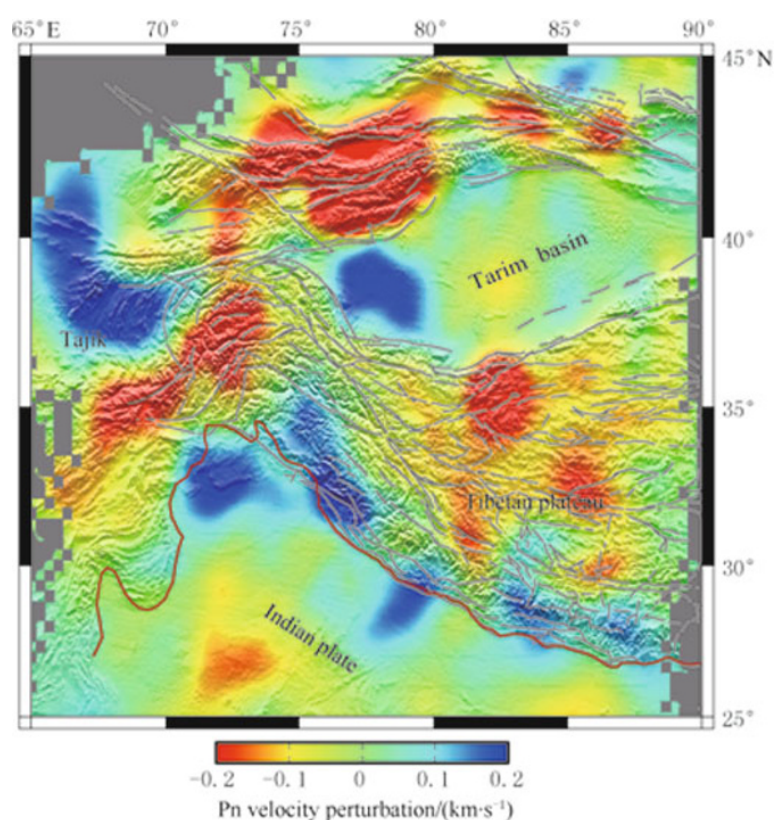

Figure 3 Inversion results for Pn velocity variations beneath Pamir and its surrounding regions. Red corresponds to low velocity and blue to high velocity. The average Pn velocity is $8.25 \mathrm{~km} / \mathrm{s}$.

Our inversion reveals significant features that correlate with surface geology: prominent high velocities exist in stable and old regions such as western Tarim, the Indian plate and the North Afghanistan block, while distinct low $\mathrm{Pn}$ velocities are found in active tectonic regions and volcanic areas, like the western Tibetan plateau, Pamir, and Tianshan.

The regional Pn results are consistent with prior studies. In the Tarim basin, although western Tarim has the prominent high velocity, the velocities of the eastern Tarim basin are close to average, consistent with previous studies on Tarim (Liang et al., 2004; Pei et al., 2007; 2011). Western Tibet displays the lowest velocity across Tibet, consistent with the previous Pn studies (Liang et al., 2004; Pei et al., 2007, 2011). Additionally, comparing the boundary between the Eurasian and Indian plates on the surface with the high velocity observed in the tomography image, we find that the Indian plate has subducted about $200 \mathrm{~km}$ underneath the Tibetan plateau in the upper mantle. A similar result was observed to occur between depths of 100 and $200 \mathrm{~km}$ in the 3D tomography (Li et al., 2008).

\subsection{Pn anisotropy}

Figure 4 shows Pn lateral anisotropy variations. The strong anisotropy is found beneath the ranges with the highest deformation, including the Indian-Eurasian collision zone and its periphery. The anisotropy results also show that the Pn anisotropy direction is parallel to the collision arc beneath the Indian-Eurasian collision zone, but it is almost perpendicular to the collision arc beneath two sides of the collision zone. These results agree to previous research (Pei et al., 2007).

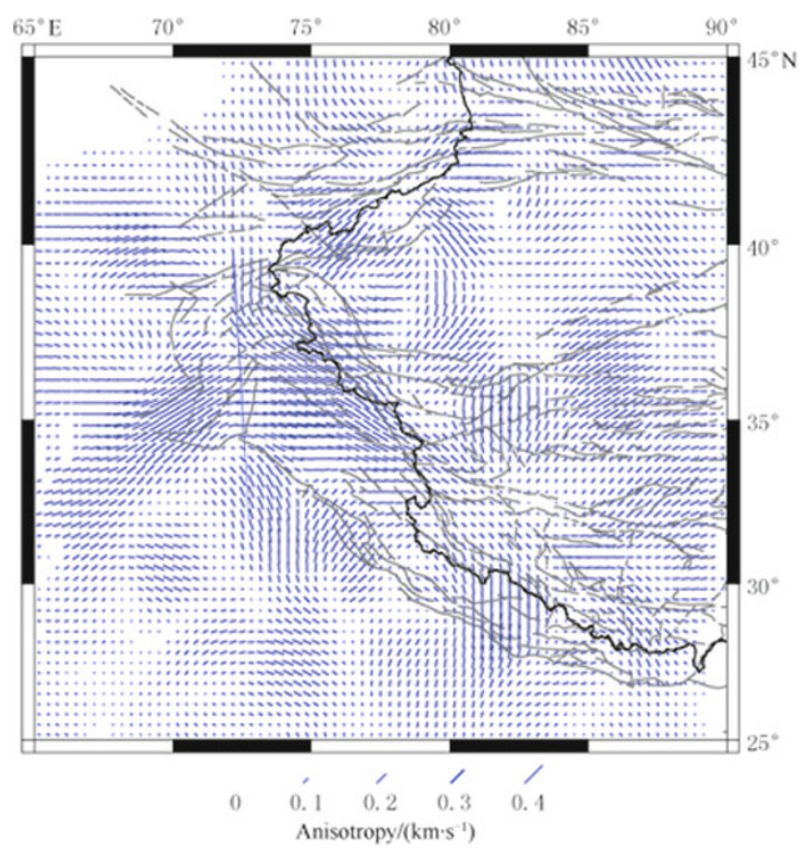

Figure 4 Inversion results for Pn lateral anisotropy variations. Each line segment is oriented along the direction of faster Pn wave propagation and its length is scaled to the amount of anisotropy.

\subsection{Checkerboard tests}

In order to evaluate the reliability of the tomographic results and the effects of ray coverage on spatial resolution, a series of checkerboard tests were applied. We created a checkerboard velocity model by assigning sinusoidal velocity and anisotropy anomalies whose fast directions are alternating at N-S and E-W to the cells of the model domain, with a background velocity of $8.25 \mathrm{~km} / \mathrm{s}$. The maximum sinusoidal velocity and anisotropy are set to have the same value of $0.3 \mathrm{~km} / \mathrm{s}$. The arrival times are calculated from the test model with the same numbers of earthquakes, stations, and ray paths as those used for the tomographic inversion of the real data. Afterward, the Gaussian noise with a standard deviation of $1.28 \mathrm{~s}$ was added to results to get the synthetic arrival times, since we conservatively assume the residuals after inversion to be noise. These synthetic arrival times were then inverted for velocity and anisotropy with the same algorithm used for the inversion of the real data. The spatial resolution is considered to be good for a region in which the checker- 
board pattern is recovered. Figure 5 shows the results of checkerboard resolution tests. The figure shows that in most of our study area, the resolution of velocity and anisotropy reaches $1^{\circ}$ and $1.5^{\circ}$, respectively. Compared
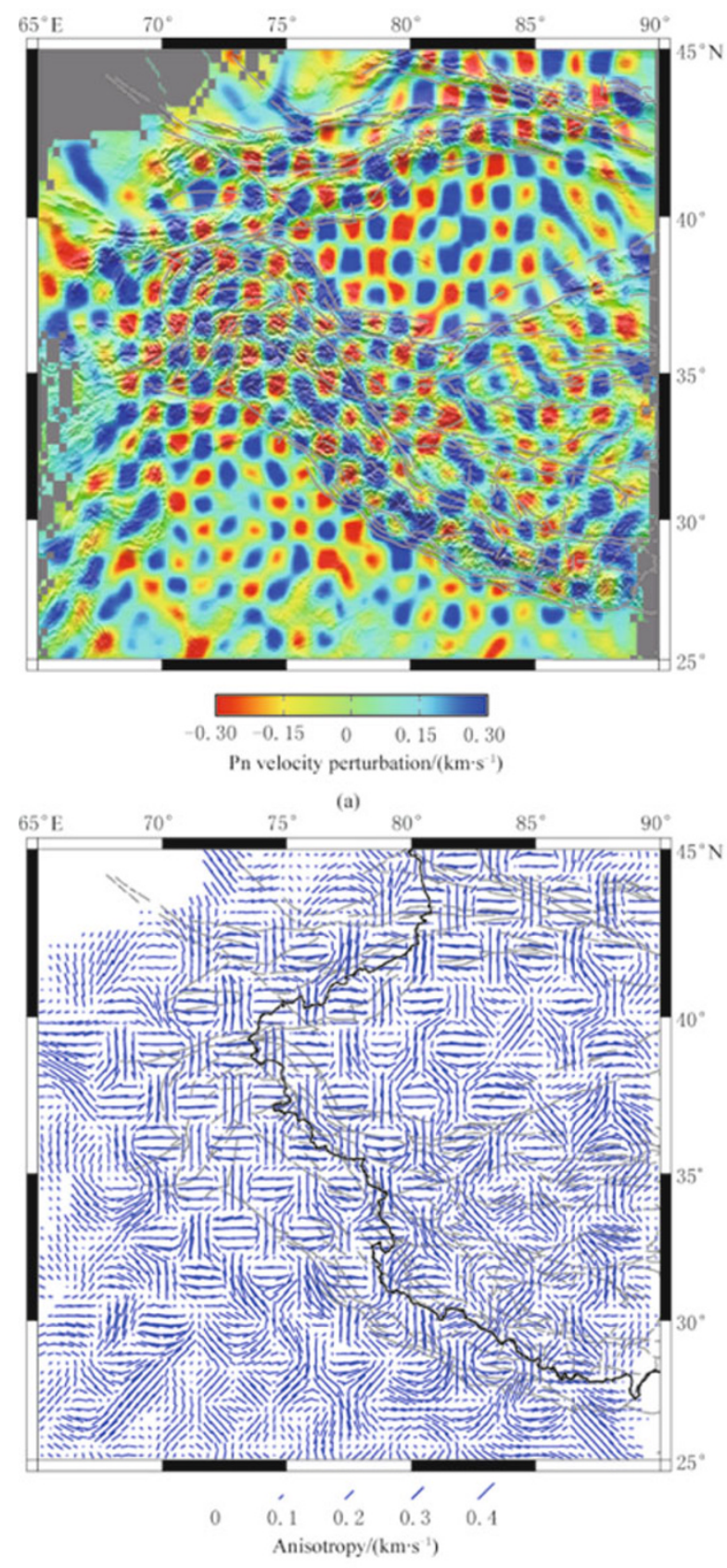

(c) to previous studies, the resolution of both velocity and anisotropy has significantly improved due to the additional travel time data used from the Xinjiang regional database.
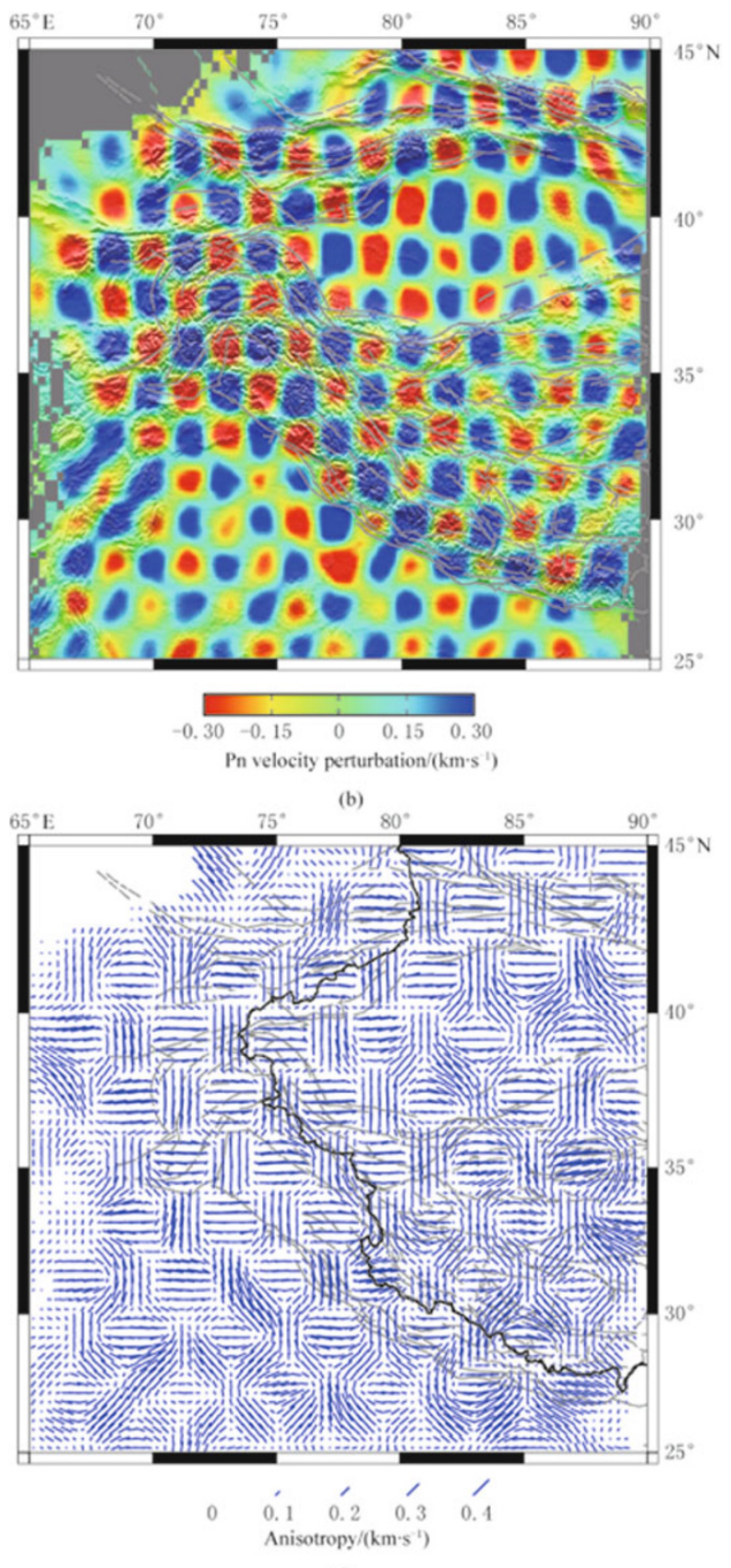

(d)

Figure 5 Checkerboard resolution tests of Pn lateral velocities in $1^{\circ} \times 1^{\circ}$ (a) and $1.5^{\circ} \times 1.5^{\circ}$ (b), and Pn lateral anisotropy in $1.5^{\circ} \times 1.5^{\circ}$ (c) and $2^{\circ} \times 2^{\circ}$ (d).

\section{Discussion}

Our results show that the Pn velocities of this region are associated with regional geological structures: high velocities are associated with cold and old plat- forms and basins such as the Tarim basin, the Indian plate and the North Afghanistan block. The low velocities occur in tectonically active areas like the western Tibetan plateau, Pamir, Tianshan and Hindu Kush. 


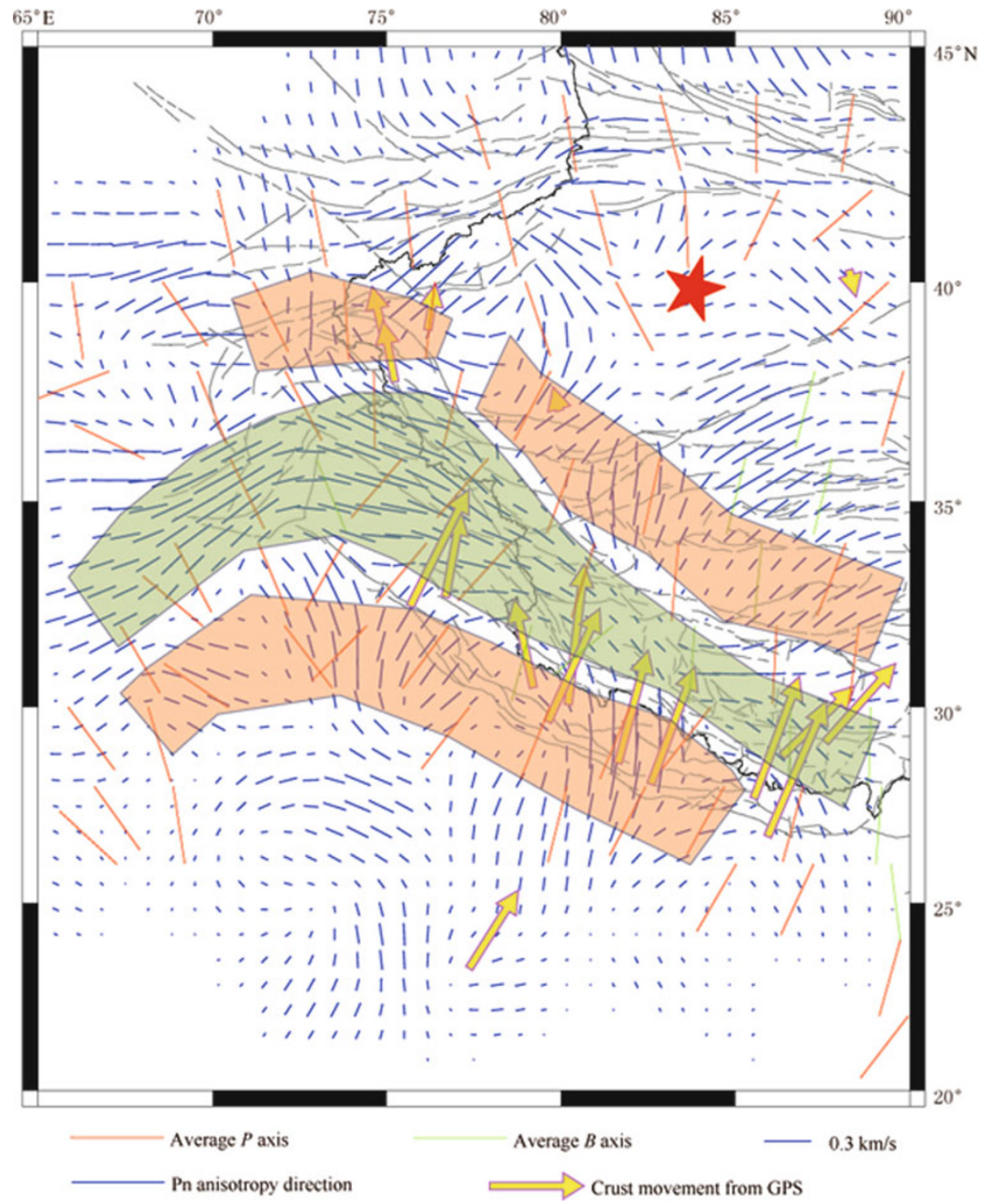

Figure 6 Comparison between tomographic anisotropy, maximum compressive stress (Xu, 2001) and crustal movement (Li et al., 2003) in Pamir and its surrounding regions. Red lines represent average orientation of maximum compressive stress obtained from earthquake focal mechanisms. A green line ( $B$ axis) is plotted when the $P$ axis is vertical. Yellow arrows represent crustal movement direction of active blocks from GPS measurements with the Tarim basin as the reference point (red star).

These velocity differences between active and stable blocks mainly result from temperature (Beghoul and Barazangi, 1995; Hearn and Ni, 1994; Hearn et al., 2004), although there are several factors that can also influence the Pn lateral velocity variations such as the pressure, material composition, water and volatile content. The stable blocks are often cold and have low heat flow on the surface, while tectonic boundaries often display higher heat flow due to uplifting hot material or volcanism.

It is widely accepted that Pn velocity anisotropy is caused by the preferred alignment of olivine crystals due to deformation of material in the uppermost man- tle. Previous studies indicated that in a region under simple shear deformation, the olivine a-axis will align itself in the direction of the maximum shear stress. This causes the fast direction of anisotropy to be parallel to the strike of shear belt. Under a region undergoing pure shear deformation, the olivine a-axis is perpendicular to the maximum compression stress, causing the fast direction to be perpendicular to the maximum compression and parallel to the direction of the maximum extension (Hearn, 1999). Pure shear is an irrotational strain or flattening strain in which, during the deformation of a body, the principal strain axes remain parallel to their respective principal stress axes, and the body is 
elongated in one direction and shortened at the other directions. Simple shear is defined as a rotational strain in which the maximum and minimum strain axes are reoriented in relation to their original positions, and which are often caused by differential movements on one set of parallel planes, resulting in internal rotation of fabric elements. The difference between pure shear and simple shear will form different anisotropy. Due to the close relationship among the anisotropy, stress and plate movement, we compare the fast direction of anisotropy to the direction of crustal movement and maximum principal compressive stress. The maximum principal compressive stress and the crustal movement were deduced from seismic moment tensors and focal mechanism solutions by $\mathrm{Xu}$ (2001) and GPS (Wang et al., 2001; Li et al., 2003), respectively.

From Figure 6 we can see that the Pn anisotropy direction is nearly perpendicular to both the direction of maximum compression and crustal movement beneath the collation zone (green shadow area). This probably resulted from pure shear deformation due to the collision and compression between the Indian and Eurasian plates. Beneath the two sides of the collision zone (orange shadow area), the fast directions of Pn are consistent with the directions of maximum principal compressive stress as well as directions of crustal movement determined from GPS (using the Tarim basin as a reference point). This suggests that simple shear (Figure 6 ) between the crust and mantle dominates the deformation.

Figure 7 shows the simple geodynamic model constructed to interpret the tomography results beneath the Indian plate, Tarim and Tajik basins. At the beginning of the Indian-Eurasian collision (PaleoceneEocene), the Paropamisus (Hindu Kush)-North PamirWest Kunlun block was an nearly E-W linear structural belt which was located on the southern margin of the Tarim-Tajik basin (Burtman and Molnar, 1993; Cowgill, 2010; Cowgill et al., 2003) (Figure 7a). The

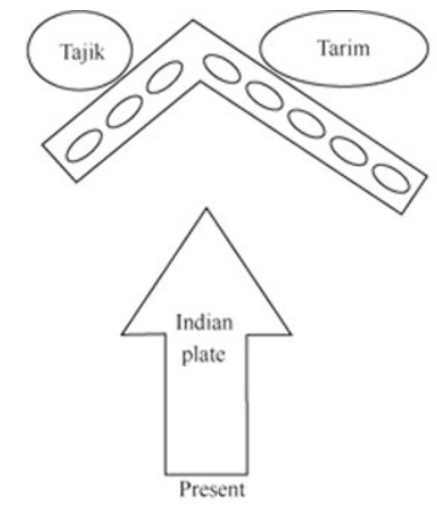

(b)

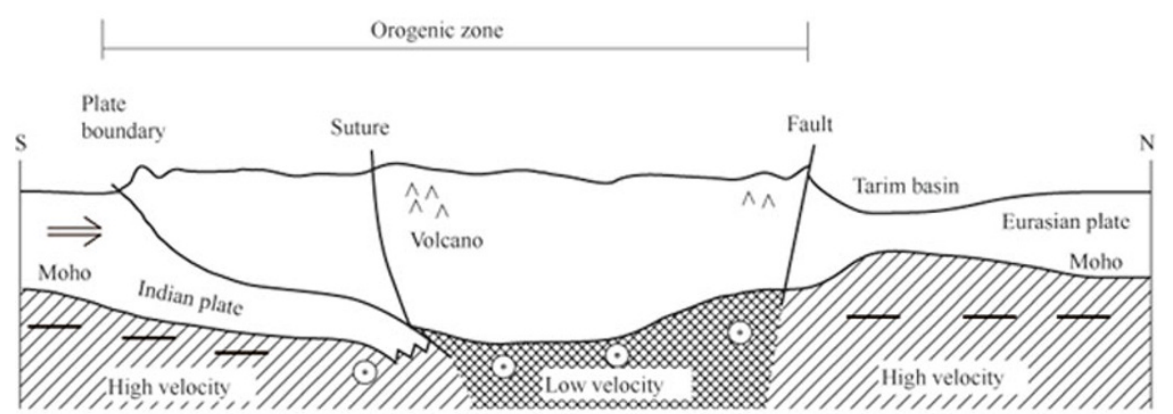

(c)

Figure 7 Geodynamic continent-continent collision cartoon located between Indian plate and Tarim and Tajik basins. Horizontal views show the collision between Indian plate and Eurasian plate before the collision (a) and present (b), and vertical section (c) shows the structure across the Indian plate, collision zone and Tarim basin. Here, the black bars under Moho indicate anisotropy with the fast direction along the direction of principle compressive stress and the circles denote the fast directions parallel to the collision belt (modified from Pei et al., 2011). 
rectangle block was gradually narrowed into upsidedown $\mathrm{V}$ shape by the northward collision of the Indian plate, and the Tarim and Tajik basins became entirely separated (Figure 7b). The Pamir from south to north was shortened by hundreds of kilometers (Cowgill et al., 2003) and became a plateau. If the circles are used to present the strain condition before the collision, they become ellipses with the longer axis perpendicular to compression direction, because the pure shear deformation will result from collision between Indian and Eurasian plates. The Pn anisotropy results agree to this pure shear deformation. Figure $7 \mathrm{c}$ shows the vertical profile across the Indian plate, collision zone and Tarim basin, in which the black bars under the Moho indicate anisotropy, with the fast direction along the principle compressive stress direction. The circles denote locations where the fast direction is parallel to the collision belt.

\section{Conclusions}

We have imaged the Pn velocity structure of Pamir and surrounding area using more datasets. Both velocity and anisotropy with high resolution have been obtained and compared with maximum principal compressive stress and crustal motion. We have arrived at the following conclusions:

1) The $P n$ velocities are particularly high in the old and stable regions such as Tarim basin, Indian plate and North Afghanistan block. Low Pn velocities occur in tectonically and/or volcanically active regions like the western Tibetan plateau, Pamir, Tianshan and Hindu Kush.

2) The $\mathrm{Pn}$ anisotropy direction is parallel to the collision arc and is nearly perpendicular to both the direction of maximum compression stress and crustal movement beneath the Indian-Eurasian collision zone. This likely is a result of pure shear deformation beneath the collision. In contrast, the fast Pn directions are consistent with the directions of the maximum principal compressive stress as well as directions of crustal movement beneath the two sides of the collision zone because of simple shear.

3) Using these results, an improved geodynamic continent-continent collision cartoon is proposed to show the anisotropy and collision mechanisms between the Indian plate and Tarim and Tajik basins.

Acknowledgements The authors greatly thank Prof. Thomas Hearn for providing Pn tomo- graphic codes and the China Earthquake Networks Center for providing us the seismic data in China. This study was financially supported jointly by the National Natural Science Foundation of China (Grant Nos. 41174036 and 41021001) and the foundation from Chinese Academy of Sciences (Grant No. KZCX2-EWQN102).

\section{References}

Burtman V S and Molnar P (1993). Geological and geophysical evidence for deep subduction of continental crust beneath the Pamir. Geol Soc Am Special Papers 281: 1-76.

Beghoul N and Barazangi M (1995). Lateral variations and azimuthal isotropy of $\mathrm{Pn}$ velocities beneath basin and range province: Comment. J Geophys Res 100: 12 45912461 .

Chang C F and Zheng S L (1973). Tectonic features of the Mount Jolmo Lungma region in southern Tibet, China. Sci Geol Sin 1: 1-12.

Cowgill E (2010). Cenozoic right-slip faulting along the eastern margin of the Pamir salient, northwestern China. Geol Soc Am Bull 122: 145-161.

Cowgill E, Yin A, Harrison T M and Wang X F (2003). Reconstruction of the Altyn Tagh fault based on $\mathrm{U}-\mathrm{Pb}$ geochronology: Role of back thrusts, mantle sutures, and heterogeneous crustal strength in forming the Tibetan Plateau. J Geophys Res 108: 2346, doi:10.1029/2002JB002080.

Cui Z X and Pei S P (2009). Study on Pn velocity and anisotropy in the uppermost mantle of the Eastern Himalayan Syntaxis and surrounding regions. Chinese $J$ Geophys 52: 2 245-2 254 (in Chinese with English abstract).

Curtis A and Woodhouse J H (1997). Crust and upper mantle shear velocity structure beneath the Tibetan plateau and surrounding regions from interevent surface wave phase velocity inversion. J Geophys Res 102: 11 78911813.

Hearn T M (1996). Anisotropic Pn tomography in the western United States. J Geophys Res 101: 8 403-8 414.

Hearn T M (1999). Uppermost mantle velocities and anisotropy beneath Europe. J Geophys Res 104: 15 12315139.

Hearn T M and Ni J F (1994). Pn velocities beneath continental collision zones: The Turkish-Iranian Plateau. Geophys J Inter 117: 273-283.

Hearn T M, Wang S Y, Ni J F, Xu Z H, Yu Y X and Zhang X D (2004). Uppermost mantle velocities beneath China and surrounding regions. J Geophys Res 109: B11301, doi:10.1029/2003JB002874.

Lei J S, Zhou H L and Zhao D P (2002). 3-D velocity structure of $\mathrm{P}$-wave in the crust and upper-mantle beneath Pamir and adjacent region. Chinese J Geophys 45: 802- 
811 (in Chinese with English abstract).

Li C, van der Hilst R D, Meltzer A S and Engdahl E R (2008). Subduction of the Indian lithosphere beneath the Tibetan Plateau and Burma. Earth Planet Sci Lett 274: 157-168.

Li F, Zhou SY, Su Y J, Li P, Deng C H, Li L and Wang L L (2011). Study on Pn-wave velocity structure and anisotropy in the Sichuan-Yunnan and its adjacent areas. Chinese J Geophys 54: 44-54 (in Chinese with English abstract).

Li Y X, Yang G H, Li Z, Guo L Q, Huang C, Zhu W Y, Fu Y, Wang Q, Jiang Z S and Wang M (2003). Movement and strain condition of active blocks in the Chinese mainland. Science in China (Series D) 46(Suppl): 82-106.

Liang C and Song X (2006). A low velocity belt beneath northern and eastern Tibetan Plateau from Pn tomography. Geophys Res Lett 33: L22306, doi:10.1029/2006GL027926.

Liang C T, Song X D and Huang J L (2004). Tomographic inversion of Pn travel times in China. J Geophys Res 109: B11304, doi:10.1029/2003JB002789.

Mahdi H and Pavlis G L (1998). Velocity variations in the crust and upper mantle beneath the Tien Shan inferred from Rayleigh wave dispersion: Implications for tectonic and dynamic processes. J Geophys Res 103: 2 693-2 703.

Molnar P and Tapponnier P (1975). Cenozoic tectonics of Asia: Effects of a continental collision. Science 189: 419426.

McNamara D E, Walter W R, Owens T J and Ammon C J (1997). Upper mantle velocity structure beneath the Tibetan Plateau from Pn travel time tomography. $J$ Geo- phys Res 102: 493-505.

Pei S P, Sun Y S and Toksöz M N (2011). Tomographic Pn and Sn velocity beneath the continental collision zone from Alps to Himalaya. J Geophys Res 116: B10311, doi:10.1029/2010JB007845.

Pei S P, Xu Z H, Wang S Y and Hearn T M (2002). Pn velocity tomography of Xinjiang, China and adjacent region. Chinese J Geophys 45: 218-225 (in Chinese with English abstract).

Pei S P, Zhao J M, Sun Y S, Xu Z H, Wang S Y, Liu H B, Rowe C A, Toksöz M N and Gao X (2007). Upper mantle seismic velocities and anisotropy in China determined through Pn and Sn tomography. J Geophys Res 112: B05312, doi:10.1029/2006JB004409.

Wang S Y, Hearn T M and Xu Z H (2001). Velocity structure of uppermost mantle beneath China continent from Pn tomography. Science in China (Series D) 31(6): 449-455 (in Chinese with English abstract).

Wang S Y, Xu Z H and Pei S P (2003). Pn velocity variation beneath China mainland and deep structure background for major earthquake generation. Chinese J Geophys 46: 779-805 (in Chinese with English abstract).

Xu Y, Liu J H, Liu F T, Zhu L R, Long H Y and Wei B (2006). Crustal velocity structure and seismic activity in the Tianshan-Pamir conjunctive zone. Chinese $J$ Geophys 49: 469-476 (in Chinese with English abstract).

Xu Z H (2001). A present-day tectonic stress map for eastern Asia region. Acta Seismologica Sinica 14(5): 524-533.

Yin A and Harrison T M (2000). Geological evolution of the Himalayan-Tibetan orogen. Annu Rev Earth Planet Sci 28: 211-280. 